\title{
RESPIRATORY RISKS IN TUNNEL CONSTRUCTION WORKERS
}

\author{
G. ARCANGELI, V. CUPELLI, M. MONTALTI, M. PRISTERA', \\ A. BALDASSERONI ${ }^{*}$ and G. GIULIANO

\begin{abstract}
Dipartimento di Scienze Ortopediche, Ricostruttive e del Lavoro - Università di Firenze ${ }^{1}$ Azienda Sanitaria di Firenze Largo P. Palagi 1-CTO - 50139 Firenze, Italy
\end{abstract}

Respiratory diseases are frequent in tunnel construction workers. A group of 144 subjects randomly selected from the population of $\mathbf{2 5 1 6}$ workers engaged in the construction of the railway tunnel under the Appennine Mountains, from Bologna to Firenze was investigated. A group of 69 males comparable for age, living area and habits was studied as a control group. Assessment of air pollutants $\left(\mathrm{NO}, \mathrm{NO}_{2}, \mathrm{SO}_{2}\right.$, total dust, silica \%) was carried out by means of fixed monitoring stations as well as personal monitors. All the subjects included in the study were examined with a standardised protocol which included physical examination, lung function tests (before and after shift work) and a questionnaire to collect respiratory symptoms. Low concentrations of environmental pollutants were evidenced. Significantly lower values of FEV 1 and PEF were determined in the worker group pared to controls. A significant decrease in respiratory parameters was shown after shift work. Variables capable of influencing the decrease in parameters include smoking habits, work activity, presence of cough and expectoration, period of the year (spirometries resulted worse in the winter time). Significantly lower values of $F E V_{1}$ and PEF were evidenced in the workers compared to controls. In spite of the present low work environmental exposure conditions, some physiologic parameters appear altered in tunnel construction workers. This may depend on a variety of noxious agents present in the working environment.

Tunnel construction work is related to respiratory disease risks due to a variety of exposures, including total and silica dust, diesel exhaust fumes, and nitrogen dioxide (1). Dust is generated by rock blasting and drilling and during transport operations; $\alpha$-quartz concentration depends on the geology at the work site. Dieselpowered machines, used in tunnel constructions, produce nitrogen dioxide and carbon monoxide (2). An increased risk of obstructive pulmonary disease (3) and acute shift work reduction in some functional respiratory parameters have been reported in tunnel construction workers (4). Decreased lung function and bronchial hyperresponsiveness are described in subjects daily exposed to nitrogen dioxide (5).

The use of environmental and personnel protection devices allows to highly reduce the workers' exposure to dust and gases. The aim of this study was to evaluate the actual occurrence of respiratory symptoms and airflow limitation in tunnel construction workers, in particular by evaluating the acute shift work respiratory response.

\section{MATERIALS AND METHODS}

The study was conducted in the area of the Appennine Mountains, where a new railway line from Bologna to Firenze, with total of $72.4 \mathrm{Km}$ of tunnel under the earth's surface, is under construction. We investigated the two major tunnels under construction, named the "Rovigo" tunnel and the "Carlone" tunnel. The underground construction includes exavation, rock support, finishing works such as the installation of electricity and road paving. The method of drilling and blasting was, and is, used. Fumes are ventilated through the tunnel cavity using a one-way ventilation system (2).

Key words: lung function; occupational respiratory disease, tunnel

Mailing address: Dr. Giulio Arcangeli Dipartimento di Scienze Ortopediche, Ricostruttive e del Lavoro, Università di Firenze

Largo P. Palagi I - CTO - 50139 Firenze, Italy

Tel. 00390554278259

Fax 00390554278130

e-mail: arcangelig@ao-careggi.toscana.it
$0394-6320(2004)$
Copyright 0 by BIOLIFE, s.a.s.

This publication and/or arlicle is for individual use only and may not be further reproduced withoul wriltcn permission trum the copyright holder.
Unauthorized reproduction may result in financial and other penallties 


\section{Environmental monitoring}

Assessment of air environmental pollutants (total dust and silica \%, $\mathrm{NO}, \mathrm{NO}_{2}, \mathrm{SO}_{2}$ ) was carried out using fixed monitoring stations. Personnel monitors during the shift work were also used for gaseous pollutants. Total dusts were collected on acrylic copolymer membrane filters and the particle mass was then measured with a microbalance. The a-quartz content was measured using the NIOSH Method 7500 (6). Concentrations of $\mathrm{NO}, \mathrm{NO}_{2}, \mathrm{SO}_{2}$ were measured with direct-reading electrochemical sensors.

\section{Population}

A group of 176 male subjects was randomly selected from the total population of 2516 workers engaged in the construction of the railway tunnel. A group of 144 subjects $(81.9 \%)$ agreed to participate in the study. As controls, we studied a group of 69 males comparable for age, living area and habits.

The demography of the groups is reported in tab. I. The distribution for job categories included: Drivers: 39 subjects $(27 \%)$, Machine operators: 39 (27\%), Carpenters: $36(25 \%)$, Miners: 17 (12\%), Electricians/ Assistants: 13 (9\%).

Smoking habit did not significantly differ between the workers in the two tunnels, or between groups of different job categories.

All the subjects included in the study were examined as follows:

1.The CECA questionnaire was used to collect respiratory symptoms

\section{Medical examination}

3.Spirometric measurements (before and after shiftwork) were performed in the sitting position (Master Screen Pneumo, Jaeger, Germany), operated by the same trained physician, in accordance with ATS guidelines (7).

In a group of twenty workers, a serial measurement of peak expiratory flow along a period of two weeks was performed. Obtained data were analysed using a specific computerized programme.

\section{Statistical methods}

The descriptive statistics of data were performed with the SPSS package. To assess the influence of different covariates on the results in terms of flowvolume curves, we tested a linear regression model, using as independent variables the different parameters of the curve (FVC, FEV1, FEF25, FEF50, FEF75, PEF) as a percentage of theoretical values, based on age, height and weight. However, the data set included measurements which were not independent.

Repeated sampling data from the same subject were correlated and they were not independent observations as needed in a common statistical analysis. As a consequence, the estimate variance is biased, resulting in too narrow a confidence interval. To cope with this problem we used a statistical technique, applying the GEE (Generalized Estimating Equation) to the general linear regression, by means of STATA xtgee command. Among the different approaches to manage the problem of autocorrelation, the GEE approach has the property of robustness against the choice of variancecovariance matrix, that is, the structure of autocorrelation. In fact, we chose the default matrix, the so called "exchangeable matrix", where rs in the different repeated measurements were considered the same.

The linear regression model was selected as the result of a backward exclusion of covariate with a t-test for the partial coefficient above $10 \%$ of probability. However, in the tables all tested models are shown. For each partial coefficient, the $95 \%$ confidence limits are shown. As referred to the percentage of expected values on the basis of theoretical equation, the partial regression coefficients can be read directly as a percentage due to that covariate. The tables show only the most informative equations among those tested, i.e. that of FEV $1 \%$ and that of $\mathrm{PEF} \%$ as independent variables.

\section{RESULTS}

The environmental monitoring (fixed monitoring) for total dust showed that $7 \%$ of the samples was higher than the TLV-TWA level, $21 \%$ was higher than $50 \%$ of the TLV-TWA level, and the remaining $72 \%$, lower than the $50 \%$. Moreover, in $19 \%$ of monitoring silica exceeded the TLV-TWA level. Total dust mean value in the "Rovigo" tunnel was $2.71 \mathrm{mg} / \mathrm{m}^{3}$, whereas it was $1.64 \mathrm{mg} / \mathrm{m}^{3}$ in the "Carlone" tunnel. No significant differences were found for silica concentrations. Significant higher values of environmental NO were found in the "Rovigo" tunnel (6.2 ppm vs. $3.4)$. On the other hand, slightly higher values of $\mathrm{NO}_{2}, \mathrm{CO}$ and $\mathrm{CO}_{2}$ were found in the "Carlone" tunnel. In personal monitoring, $\mathrm{NO}, \mathrm{NO}_{2}$ were undetectable in respectively the $13.6 \%$ and $34.9 \%$ of the samples, showing low concentrations in any case. Data, for job categories, are presented in Fig.1. 


\begin{tabular}{|c|c|c|c|c|c|c|c|c|c|c|}
\hline \multirow{3}{*}{ Job group } & \multirow{2}{*}{\multicolumn{2}{|c|}{ Age }} & \multirow{2}{*}{\multicolumn{2}{|c|}{$\begin{array}{c}\text { Years } \\
\text { working in } \\
\text { tunnel }\end{array}$}} & \multicolumn{6}{|c|}{ Smoking status } \\
\hline & & & & & \multicolumn{2}{|c|}{$\begin{array}{l}\text { Former } \\
\text { smokers }\end{array}$} & \multicolumn{2}{|c|}{ Non smokers } & \multicolumn{2}{|c|}{$\begin{array}{l}\text { Current } \\
\text { smokers }\end{array}$} \\
\hline & Mean & SD & Mean & SD & Mean & $\%$ & Mean & $\%$ & Mean & $\%$ \\
\hline $\begin{array}{l}\text { Total no. of } \\
\text { workers (144) }\end{array}$ & 40,1 & 10,1 & 12,3 & 10,1 & 34 & 24 & 40 & 28 & 60 & 49 \\
\hline $\begin{array}{l}\text { The "Rovigo" } \\
\text { tunnel (112) }\end{array}$ & 41,8 & 10,1 & 12,4 & 9,2 & 29 & 26 & 32 & 29 & 51 & 46 \\
\hline $\begin{array}{l}\text { The "Carlone" } \\
\text { Tunnel (32) }\end{array}$ & 44,1 & 8,6 & 12,1 & 12,3 & 5 & 16 & 8 & 25 & 19 & 59 \\
\hline Controls (69) & 34,7 & 9,7 & & & 14 & 20 & 27 & 39 & 28 & 41 \\
\hline
\end{tabular}

Tab. I. Characteristics of the study population

\begin{tabular}{|c|c|c|c|c|c|}
\hline Job Group & Smoking Habits & FVC \% & PEF\% & $\mathrm{FEV}_{1} \%$ & $\mathrm{FEV}_{1} / \mathrm{VC} \%$ \\
\hline \multirow{4}{*}{ Controls } & Non smokers & $107.1 \pm 9.6$ & $105.2 \pm 19.10$ & $109.8 \pm 9.6$ & $102.7 \pm 7.6$ \\
\hline & Current smokers & $110.8 \pm 9.8$ & $104.9 \pm 14.2$ & $108.9 \pm 12.2$ & $100.8 \pm 8.0$ \\
\hline & Former smokers & $103.8 \pm 15.4$ & $105.3 \pm 23.3$ & $104.3 \pm 17.0$ & $101.4 \pm 7.6$ \\
\hline & Total & $107.8 \pm 11.3$ & $105.1 \pm 18.3$ & $108.3 \pm 12.5$ & $101.7 \pm 7.7$ \\
\hline \multirow{3}{*}{$\begin{array}{l}\text { Total } \\
\text { Workers }\end{array}$} & Non smokers & $105.7 \pm 12.0$ & $104.2 \pm 17.6$ & $105.3 \pm 13.2$ & $103.1 \pm 9.0$ \\
\hline & Current smokers & $104.5 \pm 12.1$ & $92.6 \pm 14.5$ & $99.9 \pm 12.0$ & $98.3 \pm 7.5$ \\
\hline & Former smokers & $108.9 \pm 11.8$ & $99.0 \pm 12.3$ & $108, .4 \pm 12.9$ & $102.8 \pm 7.9$ \\
\hline \multirow{5}{*}{$\begin{array}{l}\text { The } \\
\text { "Rovigo" } \\
\text { Workers }\end{array}$} & Total & $105.9 \pm 12.1$ & $97.1 \pm 19.0$ & $103.3 \pm 13.1$ & $100.6 \pm 8.3$ \\
\hline & Non smokers & $103.6 \pm 11.4$ & $102.2 \pm 19.7$ & $103.9 \pm 14.11$ & $103.8 \pm 9.8$ \\
\hline & Current smokers & $102.5 \pm 12.1$ & $91.4 \pm 19.2$ & $97, .5 \pm 12.6$ & $97.9 \pm 7.7$ \\
\hline & Former smokers & $108.3 \pm 11.9$ & $99.4 \pm 16.5$ & $108.1 \pm 13.1$ & $103.0 \pm 8.4$ \\
\hline & Total & $104.3 \pm 12.0$ & $96.3 \pm 19.2$ & $101.9 \pm 13.8$ & $100.8 \pm 8.9$ \\
\hline \multirow{4}{*}{$\begin{array}{l}\text { The } \\
\text { "Carlone" } \\
\text { Workers }\end{array}$} & Non smokers & $113.9 \pm 14.3$ & $112.0 \pm 9.0$ & $110.9 \pm 9.8$ & $100.2 \pm 6.0$ \\
\hline & Current smokers & $109.9 \pm 12.0$ & $95.9 \pm 20.7$ & $106.4 \pm 10.5$ & $99.43 \pm 7.0$ \\
\hline & Former smokers & $112.1 \pm 11.1$ & $96.4 \pm 8.1$ & $109.9 \pm 11.6$ & $101.7 \pm 4.7$ \\
\hline & Total & $111.3 \pm 12.4$ & $100.0 \pm 18.1$ & $108.1 \pm 10.5$ & $100.0 \pm 6.4$ \\
\hline
\end{tabular}

Tab. II. Lung function in study population (\% of predicted values).

Values are expressed as mean $\pm S D$ 


\begin{tabular}{ccccc}
\hline & \multicolumn{2}{c}{ FEV $\%$} & \multicolumn{2}{c}{ PEF \% } \\
& $\begin{array}{c}\text { Variance } \\
\text { coefficient }\end{array}$ & P>|z| & $\begin{array}{c}\text { Variance } \\
\text { coefficient }\end{array}$ & P>|z| \\
\hline Current smokers & -5.10 & 0.021 & -9.93 & 0.001 \\
Former smokers & 0.06 & 0.983 & -2.17 & 0.545 \\
$\begin{array}{c}\text { Test after shift- } \\
\text { work }\end{array}$ & -1.03 & 0.120 & -3.01 & 0.007 \\
$\begin{array}{c}\text { Test in winter time } \\
\begin{array}{c}\text { The "Carlone" } \\
\text { tunnel }\end{array}\end{array}$ & -3.24 & 0.001 & -7.93 & 0.000 \\
$\begin{array}{c}\text { The “Rovigo" } \\
\text { tunnel }\end{array}$ & -3.53 & 0.581 & -1.64 & 0.671 \\
\hline
\end{tabular}

Tab. III. Linear

regression analysis data.

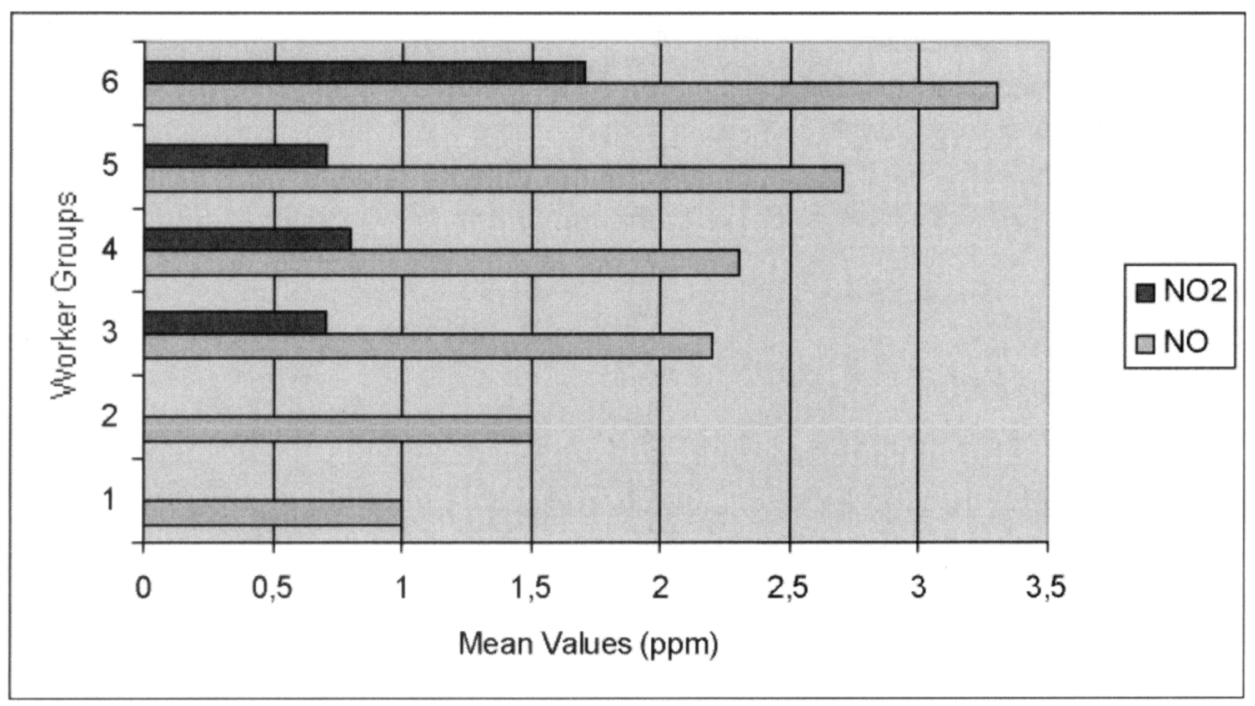

Fig. 1. Mean values of $\mathrm{NO}_{2}$ and $\mathrm{NO}$ (ppm) obtained by personal sampling, considered for job categories:

Fig. 2.Prevalence of cough and expectoration in workers and controls

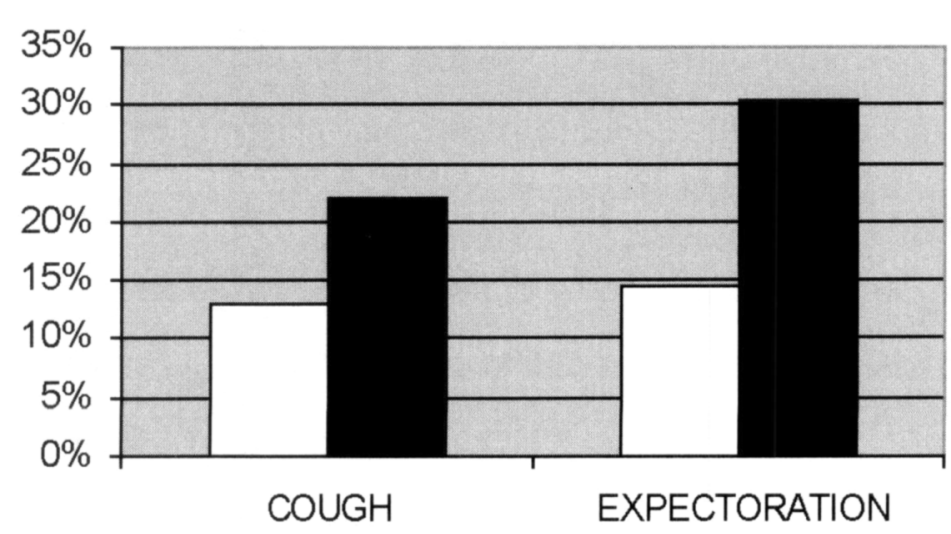





The prevalence of symptoms, obtained from the analysis of questionnaires, for controls and workers, divided also for job categories and working tunnels, is shown in figs. 2-3. Smokers presented higher significant prevalence of cough and expectoration respect to non smokers (respectively: $22 \%$ vs $11 \%$; $26 \%$ vs $14 \%$ ). The functional respiratory data are reported in Tab. II.

In Fig. 4 the variation of $\mathrm{FEV}_{1}\left(\triangle \mathrm{FEV} \mathrm{V}_{1}\right.$ after shift work) is shown in workers and controls between the registration at $7.00 \mathrm{a} . \mathrm{m}$ and at $2 \mathrm{p} . \mathrm{m}$. The $\triangle \mathrm{PEF}$ shows the same trend with less significant modification. There were no significant variations of daily PEF evaluations (amplitude \% mean daily, amplitude \% mean weekly). The linear regression analysis showed that variables capable of influencing the decrease in FEV 1 and PEF are: smoke habits, work in worse polluted conditions and execution of spirometric tests after shift-work (Tab.III).
Fig. 3. Prevalence of cough and expectoration in workers, divided by job categories (the \% is calculated for the number of workers in each job category).

Group 1 = Drivers; 2 = Machine operators; 3 = Miners; 4 = Carpenters; $5=$ Electricians $/$ Assistants

Fig. 4. \% Modification in FEV $\left(\triangle F E V_{1}\right)$ after shift work, in controls and workers in the two tunnels evaluated.

\section{DISCUSSION}

Spirometric data evidenced lower values in the group of workers compared to controls. Subjects working in the "Rovigo" tunnel (where higher values of environmental dusts were evidenced) showed lower values of FEV1 and PEF compared to workers in the other tunnel, with similar smoking habits. An annual loss of FEV1 related to work exposure is reported by some A.A. $(3,8)$. Tunnel construction workers are exposed to a variety of risk agents, including total and silica dust, diesel exhaust fumes, nitrogen dioxide; the mixture of expositions probably induces the decline in spirometric parameters.

All spirometric values were lower in smokers compared to non-smokers and former smokers. The prevalence of cough and expectoration was 
higher in workers and smokers showing that environmental work exposure and smoking habits can influence those kinds of symptoms; the increase in chronic obstructive pulmonary disease is well documented in smokers and suspected in heavy construction workers $(1,8)$.

The $\triangle F E V$, after shift work shows a significant decrease in workers. The test was performed at 7.00 a.m., before starting work activity, and at 2.00 p.m., at the end of shift work. The $\triangle \mathrm{PEF}$ shows the same trend with less significant modification. The most used spirometric parameters have a circadian rhythm, with the lowest values in the early morning and the highest values in the afternoon (9). Therefore, considering the circadian rhythm, the results obtained are underestimated and the real decrease in FEV and PEF is to be considered more evident. The effect is clearer in the "Rovigo" tunnel where environmental working conditions are worse. A temporary reduction in lung function was demonstrated in tunnel workers exposed to blasting fumes (10) and in normal humans after exposure to nitrogen dioxide (11). Multivariate analysis highlights the fact that variables capable of influencing a decrease in $\mathrm{FEV}_{1}$ and PEF are smoking habits, working in worse polluted conditions and execution of spirometric tests after shift-work.

On the whole, the results of this study show that some physiologic parameters appear altered in tunnel construction workers and suggest that better control of their occupational exposure is needed.

\section{REFERENCES}

1. Sullivan P.A., K.M. Bang, F.J. Hearl and G.R. Wagner. 1995. Respiratory disease risks in the construction industry. Occup. Med. 10:313.

2. Bakke B., P: Stewart, B. Ulvestad and W. Eduard. 2001. Dust and gas exposure in tunnel construction work. A.I.H.A.J. 62:457.

3. Ulvestad B., B. Bakke, E: Melbostad, P. Fugherund, J. Kongerund and M.B. Lund. 2000. Tunnel workers are at increased risk of obstuctive pulmonary disease. Thorax 55:277.

4. Kessel R., M. Redl, R. Mauermayer and G.J. Praml. 1989. Changes in lung function after working with the shotcrete lining method under compressed conditions. Br. J. Ind. Med. 46:128.

5. Blomberg A., M.T. Krishna, R. Helleday, M.Soderberg., M.C. Ledin, F.J. Kelly, A.J. Frew, S.T. Holgate and T. Sandstrom. 1999. Persistent airway inflammation and lung function responses after repeated daily exposure to nitrogen dioxide. Am. J. Respir. Crit. Care 159:536.

6. National Institute for Occupational Safety and Health (NIOSH). 1998. Silica, Crystalline, by XRD Method 7500. In NIOSH Manual of Analytical Methods, $4^{\mathrm{th}}$ ed. (DHS publication no. 98-119) Cincinnati, OH, USA

7. American Thoracic Society. 1987. Standardization of spirometry: 1987 update. Am. Res. Respir. Dis. 136:1285.

8. Ulvestad B., B. Bakke, W. Eduard W, J. Kongerund and M.B. Lund. 2001. Cumulative exposure to dust causes accelerated decline in lung function in tunnel workers. Occup. Environ. Med. 58:663.

9. Quackenboss J.J., M.D. Lebowitz and M. Krzyzanowski. 1991. The normal range of diurnal changes in peck expiratory flow rates. Relationship to symptoms and respiratory disease. Am. Rev. Respir. Dis. 143:323.

10. Bakke B., B. Ulvestad B, P. Stewart, M.B. Lund and W. Eduard. 2001. Effects of blasting fumes on exposure and short-term lung function changes in tunnel construction workers. Scand. J. Work Environ. Health 27:250.

11. Frampton M.W., P.E. Morrow and C. Cox. 1991. Effects of nitrogen dioxide exposure on pulmonary function and airway reactivity in normal humans. Am. Rev. Respir. Dis. 143:522. 